and two oblique, rather curved stripes formed of dense white hairs: the elytra have several rows of punctures, with the interstices minutely granulated; each elytrum has a discoidal white dot a little below the midd!e, and, in several specimens, there is also an indistinct one between it and the apex on each side of the abdomen underneath, as in $L$ arcticus, are four yellowish round spots formed of hairs. In some specimens the pubescence has a tawny hue, in others the indistinct spot is obliterated. [Taken in Canada.]

[198.] 265. Leryrus Gemellus Kirby.-Plate v., fig. 7.-Length of body $7 \mathrm{I} / 4$ lines. A single specimen taken in Lat. $65^{\circ}$.

Body very black, covered more or less with decumbent white hairs, and also with minute tubercles. Rostrum as in L. Colon: prothorax ridged, confluently tuberculated, minutely punctured between the tubercles, marked on each side with an oblique stripe composed of white hairs: elytra confluently tuberculated, with five pairs of longitudinal streaks, converging towards the apex: the first and fifth including the rest.

[199.] 266. Cleonis vittatus Kirby.-Length of body $31 / 2-5$ lines. Several specimens taken in the Expedition.

Body narrow, black, covered with decumbent hoary pile. Head thickly covered with hairs, but on each side from the eye to the insertion of the antennae, the hairs are less dense, which gives the appearance of a blackish stripe; rostrum thick, shorter than the prothorax, obsoletely ridged, punctured: prothorax obsoletely ridged, punctured with rather large scattered punctures, often concealed by the hairs, with three blackish stripes, produced as in the head by the hairs being thinner: the elytra also have three similar stripes, and are punctured in rows: the abdomen underneath appears as if dotted with black from the same cause.

\title{
ZOOLOGICAL PARALLELISM.
}

BY PROF. JAMES T. BELL, BELLEVILLE.

In making a general survey of the Animal Kingdom, it is impossible to avoid being struck by the remarkable parallelism which exists between the several orders and families, and even genera and species, that compose the respective classes into which it is divided, and which reveals itself in the representative types that abound throughout its whole extent. 
Thus if we take the mammalia as our starting point, we shall find that the carnivora are represented among the birds by the raptores, among the reptiles by the crocodiles and serpents, among the insects by the predaceous beetles, ichneumons, and dragon-flies, among the annulosa by the spiders, crabs, lobsters, \&c., among the mollusks by the cuttle-fish and by some of the gastropods and a few brachiopods, and among the radiates by the sea-urchins, star-fish, sea-anemones, and many of the animalculae.

Confining our observation to the parallelism between the manmalia and the birds on the one hand, and the insects on the other, we find that the carnivorous mammals are well represented among the Coleoptera is follows:-The felidae, the typical carnivora, by the Cicindelidae, whose resemblance is acknowledged in their vernacular name of "tiger-beetles." The canidae, dogs, wolves, foxes, are fitly represented by the Carabidae, the wasel tribe by the Staphylindac, and the hyaenas and vultures by the Silphidae; while the marine carnivora, the seals and whales, find their representatives in the Dytiscidac and Hydroidae; and the various species o[ rapionial birds are no less fittingly typified by the Libcllulidac, ichneunon-tlies, sphexes, and the predaceous wasps and hornets; not forgetting the ants, which have a highly devcloped carnivorous organization.

I shall not follow out in detail the obvious resemblances that may be olsserved betwcen the pachydermatous animals and the Lucanidae and other dendrophagous insects, as well as between the bovine, equine, and ovine tribes, and the gallinaceous and cursorial birds on the one hand, and part of the Scarabeidae and Chrysomelidae, and most of the Orthoptera on the other; or those not less remarkable that exist between the goat, deer and antelope families, and the Cerambyx, Clytus, and Leptura genera.

If the hints I have thrown out should induce some of my younger entomological brethren to study more closely the relation of the Insects to the other members of the Animal Kingdom, my intention will be amply fulfilled.

\section{PERSONAL}

BARON OSTEN SACKEN.-We regret to announce that this eminent Dipterist has returned to Europe "for an indefinite period, several years, or perhaps for ever." His last contribution to American Entomology will, 